\title{
Duas culturas - arte urbana, índio citadino - em contextos (in)culturais ${ }^{1}$ Two cultures - urban art, urban indian - in (in)cultural contexts
}

\author{
Marcos Antônio Bessa-Oliveira² ${ }^{2}$ Leonardo Reinaltt Simão³
}

\begin{abstract}
Resumo
"Dois pesos, duas medidas": um ditado popular que, podemos dizer, se relaciona diretamente à (di)simulação das fronteiras na arte urbana bem como para a cultura do índio citadino. Mas apesar da iniquidade estabelecer-se para as culturas de toda a América Latina vistas como culturas periféricas, nossa discussão estará concentrada na arte e no índio "civilizados" em Campo Grande, MS-Brasil. Trataremos do processo de civilização forçado (da arte e dos índios locais), postos pelos discursos que tomam da Estética Moderna para edificar fronteiras (di)simuladas, que tomam a produção da arte urbana e a cultura do índio citadino com tratamentos e formas completamente diferentes das estabelecidas para a produção artística do homem branco e do morador dos centros. Partindo deste princípio, a ideia é discutir que apenas a formulação de uma Estética Periférica pode tomar a prática artística ou as culturas excluídas pelos discursos hegemônicos de qualquer "centro" do poder como produção de arte, cultura e conhecimentos pelas suas diversalidades biográficas e geográficas sem o estabelecimento de qualquer ideia de fronteira binária.
\end{abstract}

Palavras-chaves: Arte urbana. Índio citadino. Pós-colonialismo. Estética bugresca.

\begin{abstract}
"Two weights, two measures": a popular saying that, we may say, is directly related to the (di)simulation of frontiers in urban art as well as to the culture of the urban Indian. But despite the iniquity being established for cultures throughout Latin America viewed as peripheral cultures, our discussion will be focused on the "civilized" art and Indian in Campo Grande, MS-Brazil. We will deal with the process of forced civilization (of art and local Indians), posed by the discourses they take from Modern Aesthetics to construct (dis)simulated borders, which take the production of urban art and the culture of the urban Indian with completely different treatments and forms of the established ones for the artistic production of the white man and the resident of the centers. Based on this principle, the idea is to argue that only the formulation of a Peripheral Aesthetics can take artistic practice or cultures excluded by the hegemonic discourses of any "center" of power as a production of art, culture and knowledge for their biographical and geographical diversilities without the establishment of any idea of binary frontier.
\end{abstract}

Keywords: Urban art. Urban Indian. Post-colonialism. Bugresca aesthetics.

\footnotetext{
${ }^{1}$ Este trabalho está vinculado a um Projeto de Pesquisa desenvolvido com Bolsa PIBIC/CNPq 2016 - 2017, intitulado "Estados da arte, estados do índio: situação de fronteiras por poder(es)", que por sua vez está vinculado ao Projeto de Pesquisa do orientador cadastrado na PROPP/UEMS sob o título: "Arte e Cultura na Frontera: "Paisagens" Artísticas em Cena nas "Práticas Culturais" Sul-Mato-Grossenses".

2 Doutor em Artes Visuais pelo IAR-Unicamp. Professor do Curso de Artes Cênicas (Graduação) e do Programa de Mestrado Profissional em Educação - PROFEDUC - da Universidade Estadual de Mato Grosso do Sul - UEMS na Unidade Universitária de Campo Grande - UUCG - Brasil. E-mail: marcosbessa2001@uol.com.br

${ }^{3}$ Graduando do $1^{\circ}$ ano do curso de Artes Cênicas da UEMS e Bolsista PIBIC/CNPq.
} 


\section{Introdução}

O conceito precisa de clareza bastante para estabelecer diferenças quanto a todo o concreto que deva ser submetido a sua classificação. Deve possuir bastante precisão para poder alcançar as distinções entre coisas que não são absolutamente congruentes. Sua exclusividade, contudo, não deve ser tão estreita quanto aquela que o nome deve ter em relação ao indivíduo, à sua identidade e à sua identificabilidade. Nesse sentido, o conceito não é tanto o instrumento adequado para a criatura que lembra como o apropriado para a criatura que se previne: ela busca levar a cabo aquilo que ainda não está naturalmente estabelecido. (BLUMENBERG, 2013, p. 47).

As populações indígenas do estado do Mato Grosso do Sul, e em especial a população indígena que habita as chamadas "aldeias urbanas" da capital Campo Grande, vivem uma crise de identidade que se acentua cada vez mais; pois a quebra das fronteiras físicas que comumente existem entre as terras indígenas, nas práticas indígenas e nas áreas urbanas e nos fazeres socializados são o expoente final do processo de recolonização ao qual esse sensível arquétipo social subalterno tem sido submetido.

Do mesmo jeito, as produções e artefatos culturais (práticas artísticas) que não se inscrevem como obras de arte, tendo o discurso de arte falseado pelo poder da arte ora instituído nos discursos hegemônicos, são recolonializadas nos guetos das cidades, especialmente nas grandes cidades (ou em capitais menores como Campo Grande), cerceadas em uma espécie de fronteira-contexto específico da exclusão. Falamos em recolonização considerando o atual cenário posto aos povos indígenas e a manutenção das suas práticas. Bem como tratamos da produção artística urbana que não está inscrita na noção de obra de arte ou como produtoras de conhecimentos. Ambos - índios e arte local - ainda que "socializados" pela cultura branca ou pelo sistema da arte estatal: uma ideia que não os tomam como produção artística nem do contexto sociocultural do próprio índio, nem como representação do marginal excluído; menos ainda do contexto social cultural esbranquiçado à guisa de muito "pó de arroz" ou reconhecidos pelas instituições e discursos que validam o que é ou não arte.

Essa recolonização se dá através das lacunas deixadas pelas políticas-públicas estabelecidas pelo projeto indigenista ineficaz do Estado-nação que relega ao índio uma proteção superficial e para não adentrar na inflamável questão da demarcação de terras que atinge os interesses da classe detentora do poder econômico na região. O mesmo ocorre em relação à produção artístico-cultural urbana em Mato Grosso do Sul que não é reconhecida como produto artístico pelo sistema estatal que apenas a ampara a título de institucionalização evitando o enfrentamento direto em relação à destruição, por exemplo, do que é considerado "patrimônio público" só que estatal.

Ambos, indígena e produção artística urbana, acabam sendo limitados entre fronteiras estabelecidas por discursos que entrincheiram tanto os indígenas e suas práticas artístico-culturais bem como as produções urbanas de serem reconhecidas como tais. Há, portanto, um discurso imperante que (de)limita entre fronteiras reais e virtuais o espaço de enunciação, atuação e representação dessas práticas como resultados das classes como identidades culturais - tornando as práticas indígenas e a arte urbana meros objetos de exposição sobre esses sujeitos sem relações socioculturais.

Da problemática da classe indígena ressalta a (pre)ocupação do/no solo: classe essa que tem uma simbiótica relação com a produção agropecuária que termina assentada na velha relação de troca de um "espelho" pelo lugar social e epistêmico do índio. Lugar esse que talvez desde o início da colonização no século XVI tenha desaparecido graças às mordaças, vendas e amarras impostas aos índios em todos os seus âmbitos sociais, culturais e etnográficos. Sobre a produção urbana é possível ressaltar que sua problemática está na ideia de (des)organização dos espaços 
sociais. Um espaço social que está circunscrito pelas fronteiras reflexivas político-sociais estabelecidas pelas leis de uso e ocupação das cidades pelos sujeitos "sociais". Esses "espelhos" não são colocados como um simples objeto que reflete os sujeitos das ações, mas são postos como uma proposta para que o índio e os sujeitos à margem do contexto social-urbano olhem para si mesmos de outro ponto de vista: o ponto de vista do sujeito dominante que tem seu reflexo (in)posto e sobreposto aos índios e marginais da ótica periférica - ainda na contemporaneidade para que esses vejam a si próprios como objetos inexistentes e sem (re)existência.

\begin{abstract}
Trata-se aqui da relação total entre a linguagem e o que podemos denominar "realidade". Os objetos não existem no mundo independentemente da linguagem que utilizamos para descrevê-los? Num sentido, é óbvio que sim. Para voltarmos ao exemplo familiar discutido anteriormente: uma pedra ainda existe a despeito de nossas descrições dela (ver Hall, 1997, p. 45). Entretanto, a identificação que fazemos da mesma como "pedra" só é possível devido a uma forma particular de classificar os objetos e de atribuir significado aos mesmos (isto é, a palavra pedra vista como parte de um sistema de classificação que diferencia pedra de ferro, madeira, etc.; ou, por outro lado, num sistema de classificação diferente - a pedra, em oposição ao penedo, rocha, seixo, etc.). Os objetos certamente existem também fora destes sistemas de significação (cada qual dando um significado diferente a mesma coisa, a "pedra"); os objetos certamente existem, mas eles não podem ser definidos como "pedras", ou como qualquer outra coisa, a não ser que haja uma linguagem ou sistema de significação capaz de classificá-los dessa forma, dando-lhes um sentido, ao distingui-los de outros objetos: (HALL, 1997, p. 27).
\end{abstract}

Essa proposta assume no meio urbano um disfarce utópico que quase convence a todos de que o índio urbanizado (inclusive um convencimento ao próprio sujeito que sofre a ação de recolonização), exilado de seu lugar social e epistêmico, pode e deve pensar epistemologicamente como aqueles que se encontram na posição de dominantes (os brancos). Do mesmo jeito os reflexos desse "espelho" vão tentar favorecer a determinados grupos e artistas - na contemporaneidade quando falamos de alguns grafiteiros já institucionalizados - de que esse discurso artístico (antes posicionado como discurso da revolução contra o sistema) também é corroborado pelas ações sociais do Estado-nação. ${ }^{4}$

Se nos afastamos, entretanto, da ideia de olhar externo posto à subalternidade indígena e às práticas culturais/artísticas urbanas e, pelo contrário, mergulhamos nela, para que a partir delas nós a $\operatorname{sintamos}^{5}$ (a condição de subalternidade desses sujeitos), verificamos que, na grande verdade, tratase de uma nova escravidão em relação ao indígena e de mais repressão às modalidades urbanas de arte ${ }^{6}$; um novo esbulho de tudo o que consubstancia o índio contemporâneo a uma aura de identidade indígena que se mantém desde a história colonial do Brasil: sua cultura, suas práticas culturais (tomadas como artísticas ou não); sua etnografia, suas histórias, suas crenças religiosas etc; ou às novas formas de exclusão daquelas produções marginais (urbanas) vistas como não arte, que acabam por relegar a ambos (índio e produção artística) o lugar de oposição ao que é posto pelo discurso colonial moderno e pelos discursos dos poderes contemporâneos como arte e cultura.

Essas histórias de ambos (arte periférica e situação indígena) não se ilustram pelas questões já postas historicamente (pelos discursos inpostos da História e Teorias das Artes tradicionais,

\footnotetext{
4 Aqui cabe um registro: quando tratamos desta questão, estamos falando em relação a determinados grupos artísticos - cênicos, grafiteiros, artistas visuais, bailarinos etc - que ainda são levados a pensar que desenvolvem obras artísticas independentes com o apoio do Estado. Quando, na verdade, pobres mortais, são manipulados e levados a desenvolver exatamente aquilo que o poder público e os discursos dominantes definem como arte, cultura e produção de conhecimentos.

5 Grafa-se o termo tendo em vista que é impossível falar pelo outro quando se toma como aporte teórico as perspectivas teóricas culturais. Nesse sentido, o discurso aqui posto se inscreve na relação que se estabelece entre o observar de perto contra a ideia de leitor distante.

6 Haja vista que incluir, neste caso, acaba por coibir a ação dos discursos que são contra o discurso hegemônico instituído pelos sistemas de poder; sejam pelos discursos históricos da arte ou o discurso europeu (modernos), sejam pelos discursos contemporâneos: político, econômico, social e também do sistema da arte.
} 
por exemplo), mas podem ser reapresentadas historicamente por uma perspectiva de história outra que considera as fronteiras postas pelos sistemas dominantes hegemônicos, tanto nas barreiras reais como nas fronteiras virtuais, estabelecendo-as (barreiras e fronteiras) como objetos de/para segregação do outro a partir da falsa noção de amparo social e cultural dados, por exemplo, pelo Estado-nação. ${ }^{7}$ Aqui se estabelece uma outra questão que faz jus lembrarmos. Se a fronteira que parece sempre separar é em algum momento também sinal de aproximação, porque faz unir as diferenças e o que se tenta separar (HISSA, 2002).

Nesta situação, a barra (/) como investidura de limite acaba por isolar o indígena ou o sujeito da prática cultural urbana, não circunscrita no sistema da arte, dentro do campo da aproximação ao dominante (a cidade), pelo cerceamento/ cercamento das suas práticas culturais e sociais, em um dado lugar; tendo seus discursos enfraquecidos, pelas forças dominantes do discurso branco, como epistêmico. Ou seja, o índio acaba sendo posto em aproximação do branco nesta situação de aldeização urbana (dentro das fronteiras reais estabelecidas como aldeia $\mathrm{X}$ cidade), mas acaba sendo isolado, pelo domínio do branco mais uma vez (que estabelece o distanciamento com as fronteiras virtuais - cultural e socialmente falando), do contexto social branco dominante. E a produção cultural artística do "favelado" acaba inscrita dentro das paredes dos barracos de madeira ou alvenaria mal construídos porque não polarizam os discursos postos pelo sistema dominante que impede a fixação das imagens produzidas por essas obras artísticas em qualquer lugar das cidades. Por esta razão é que essa história do índio, por exemplo, não tem ilustração, mas Darci Ribeiro enfatiza-a ao afirmar que desde os primórdios luso-brasileiros.
A contradição entre os propósitos políticos da Coroa e dos jesuítas, de um lado, e o imediatismo dos traficantes de índios, do outro, não se resolveu nunca por uma decisão real pela liberdade ou pelo cativeiro. A legislação que regula a matéria é a mais contraditória e hipócrita que se possa encontrar. Decreta dezenas de vezes guerra justa contra índios tidos como culpados de grandes agravos ou simplesmente hostis para, a seguir, coibi-las e, depois, tornar a autorizá-las, num ciclo sem fim de iniquidade e falsidade. (RIBEIRO, 1995, p. 101).

Como também enfatiza Stuart Hall ao fazer afirmativas sobre a distribuição de riquezas, transposta aqui para a problemática relação entre arte $\mathrm{X}$ poder, ao assinalar que:

De forma similar, a distribuição da riqueza e dos recursos econômicos tem efeitos materiais reais e tangíveis para os ricos e os pobres da sociedade. Entretanto, a questão sobre a distribuição da riqueza vigente, se esta é ou não "justa”, é uma questão de significado - isto quer dizer, depende de como são definidas "justiça" e "equidade"; e nossas ações econômicas serão determinadas, em parte, segundo a posição que tomarmos com respeito a estas definições. Consequentemente, podemos dizer que as práticas econômicas ocorrem e produzem efeitos dentro da referência discursiva daquilo que compreendemos como sendo justo e injusto - elas dependem e são "relevantes para o significado" e, portanto, "práticas culturais". Como diria Foucault, a cada momento particular, o funcionamento da economia depende da formação discursiva da sociedade. É óbvio que isto não significa que os processos econômicos tenham sido reduzidos aos discursos e à linguagem. Significa que a dimensão discursiva ou de significado é uma das condições constitutivas do funcionamento da economia. O "econômico", por assim dizer, não poderia funcionar nem teria efeitos reais sem a "cultura" ou fora dos significados e dos discursos. A cultura é, portanto, nestes exemplos, uma parte constitutiva do "político" e do "econômico", da mesma forma que o "político" e o "econômico" são, por sua vez, parte constitutiva da cultura e a ela impõem limites. (HALL, 1997, p. 32-33).

Desta forma, fica claro que cultura dominante, exclusão de culturas periféricas e inclusão de algumas culturas como dominantes são todas postas a partir

\footnotetext{
${ }^{7}$ A perspectiva de história outra de que falamos toma, por exemplo, da ideia de que tudo que se produz nos lugares não circunscritos nos espaços hegemônicos também são produções artísticas, culturais e produtoras de conhecimentos desses lugares e sujeitos sem, obrigatoriamente, passarem pelos discursos cronológicos e características teórico-formais estabelecidos pela História e Teoria das Artes europeias e norte-americanas.
} 
de uma única perspectiva: questão política-partidária e que no Brasil nominamos de partidarismos e/ou apadrinhamentos diariamente postos.

A noção de recolonização que propomos neste artigo, que consiste na "realocação" de aldeias do interior para os centros urbanos do Mato Grosso do Sul ou o "simples" zoneamento de áreas indígenas dentro das áreas urbanizadas das cidades, que também coíbe a repercussão nos espaços sociais da produção artístico-cultural periférica, tornando-a limitada aos contextos periféricos das cidades, está concentrada na ideia de que "justamente, o êxito do sistemamundo colonial/moderno reside em levar os sujeitos socialmente situados no lado oprimido da diferença colonial a pensar epistemologicamente como aqueles que se encontram em posições dominantes" (GROSFOGUEL, 2008, p. 119) e, igualmente, na constatação de que

Ao quebrar a ligação entre o sujeito da enunciação e o lugar epistêmico étnico-racial/sexual/de gênero, a filosofia e as ciências ocidentais conseguem gerar um mito sobre um conhecimento universal Verdadeiro que encobre, isto é, que oculta não só aquele que fala como também o lugar epistêmico geopolítico e corpo-político das estruturas de poder/conhecimento colonial, a partir do qual o sujeito se pronuncia. (GROSFOGUEL, 2008, p. 119).

Isto é, inserindo o índio na cidade (que é a materialização do pensamento capitalista/colonial/ moderno na contemporaneidade) furta-se dele a capacidade de alcançar seu corpo-política, dispensando seu discurso por ser "pessoal", incapaz de alcançar uma "verdade universal" que possa fazer emergir um discurso descolonial capaz de representar sua voz frente aos efeitos silenciadores da atuação nada silenciosa dos que detém o poder e os domina. Ainda esse corpo-(não)política indígena é marginalizado através de uma nova configuração de fronteira que, ao contrário das cercas de arames e postes dos latifúndios, deixaram de ser exclusivamente físicas para oporem-se também como fronteiras virtuais.
Do mesmo jeito a produção urbana - ou a produção que não é urbanizada, pensando de uma ótica de que o urbano está localizado nos espaços das cidades como um todo, que não está em espaços excluídos pelos limites impostos - tem inviabilizado um discurso que fala por si audível pelos discursos dos centros exatamente por situarem-se em lugares de inexpressão em relação aos lugares enunciativos expressivos.

Neste contexto, dominante sobre dominado, que se estabelecem os dualismos e fronteiras que inscrevem a relação hoje posta: índio (não-humano) $\mathrm{X}$ branco (humano), cultura (branca) X não-cultura (indígena), arte (branca) X práticas artesanais (indígena), religião(branca)X ritualística (indígena), roupa (branco) X nudez (indígena), arte X não-arte, cultura de rua $\mathrm{X}$ cultura social, grafite $\mathrm{X}$ picho, entre outros tantos des-tratados pelos sistemas. Como também é neste sentido que a fronteira, como já ressaltado antes, separa, mas também aproxima pela ótica da construção discursiva da exclusão. Pois, se por um lado um discurso estatal reforça a ideia de aproximação ao trazer esses sujeitos para dentro das cidades (índios aldeados ou galerização/ museologização de algumas práticas artísticas suburbanas), outro discurso, de lado oposto separa, com peso ainda maior: e afasta para muito longe esses povos indígenas e artistas dos seus convívios sociais e culturais brancos e institucionais ainda que aqueles estejam vivendo dentro das cidades.

Esse discurso afasta-os pela aproximação tendo em vista que obriga aos indígenas pactuarem das construções discursivas hegemônicas postas pelo homem branco da história: orna-se "humano" pelo registro identitário documental (RG) imposto pelo branco; por tomar da cultura branca como sua; e por ter suas práticas artesanais construídas para alegoria dos brancos - fazendo com que essas sejam vistas como produções culturais, não mais como artefatos utilitários ou artesanais - já que elas passam a enfeitar as paredes das grandes casas; aceitar a catequização pelas religiões branca e quase total abandono das suas ritualísticas indígena; cobertura por roupas 
dos brancos dos corpos que antes viviam desnudos e que agora tem nas vestes indígenas caráter apenas paramentário para as festas dos brancos. Como também afasta os sujeitos que (des)organizam as cidades, levando-os para dentro das instituições dos poderes artísticos, coibindo sua atuação livre e promovendo a institucionalização dos fazeres artísticos que dicotomiza poética e estética e limitam os discursos dos que já não falavam. ${ }^{8}$

Essa nova configuração de fronteira é virtual para o indígena como também para o artista das ruas, estabelecida pelo poder discursivo colonial/ capitalista/moderno, porque dá ao indígena não uma identidade, mas sim uma identificação em relação ao contexto sociocultural branco e promove para o artista a configuração de uma arte politiqueira que também o identifica (registram) aos órgãos das leis.

O índio e o artista periférico no/do meio urbano são e estabelecem-se como as próprias fronteiras, os limites, as barreiras que não se devem ultrapassar onde quer que esses sujeitos subalternizados estejam impostos. Pois sobre as suas peles esses sujeitos não-brancos ou sujeitos excluídos pelo sistema político-artístico trazem (na cor, na face, no traço, nas roupas, nos desenhos tatuados ou pintados) uma sentença de condenação, quase de morte, da invisibilidade, da incomunicabilidade, da intraduzibilidade em todo e qualquer discurso que tente fazer emergir deles próprios, frente aos discursos dominantes, ações verdadeiramente efetivas: talvez por que sejam discursos produzidos com quase a mesma perspectiva subalternizada e a partir dela em relação aos discursos dominantes, não tendo por instrumento teórico nenhum pensamento que se insira nas bases da colonialidade imperial e não sendo senão um grito ininteligível de um corpoestranho em meio ao que os aprisionam (Estado- nação) aparentando abriga-los. Igualmente, sob suas peles, esses povos trazem a ancestralidade e uma alma indígena brasileira nunca tocadas e reconhecidas pelo homem branco como aqueles que são de fato donos das terras onde, nós brancos (pardos, negros, mulatos, cafuzos e não-brancos tidos como brancos) não os reconhecemos como donos dos milhares de corpos ali e aqui - pela extensão total do território nacional brasileiro sepultados.

Do mesmo jeito, sob a pele do artista marginalizado pelo sistema, "vemos" os sentimentos de exclusão e repressão ilustrados nos trabalhos artísticos dos muros excluídos das cidades porque não os reconhecemos como práticas e respostas da sua cultura particular.

A referida fronteira (real e imaginária, de concreto ou virtual) não deixa de pesar sobre os ombros dos condenados os seus limites intransponíveis por não se estabelecer exclusivamente de maneira física, mas permite por aproximação aos sujeitos que as estabelecem político, econômico e socioculturalmente, que ocupam o mesmo "lugar social" do "índio urbanizado" ou do artista de rua, fazer vistas grossas para esses lugares epistêmicos do índio ou do marginal que existem em potencial.

Esses lugares epistêmicos aos quais nos referimos surgem em razão de estarem os nossos conhecimentos (artísticos e como produtores de conhecimentos a partir de nossos próprios conhecimentos; não falaremos em científicos) sempre situados em um determinado lugar, o lugar da subalternização, nas estruturas (entre as fronteiras estabelecidas) pelo/do poder, não sendo possível a ninguém escapar às hierarquias sexuais, de gênero e, como nos interessa em especial, às questões de identidades dos indígenas e da arte urbana: de

\footnotetext{
8 Aqui há outra questão a ser ressaltada: em Mato Grosso do Sul, bem como na grande maioria dos lugares geográficos nacionais, a produção artística reconhecida como tal já enfrenta a falta de apoio e valorização pública ou privada. Por exemplo, bem recentemente um acervo artístico de um dos nomes mais reconhecidos da pintura local, de uma "importante" instituição museológica de Campo Grande-MS, está sendo doado para ser cuidado por outra instituição da cidade porque a primeira não tem os devidos recursos e investimentos para manutenção de obras daquele valor. Neste sentido, uma discussão está sendo posta em um breve texto que um dos autores deste artigo está escrevendo sob o título: "Nem gostamos tanto assim de Lídia Baís!" a ser publicado em breve.
} 
classe, espirituais, linguísticas, geográficas, raciais e artísticas do sistema patriarcal/capitalista/colonial/ moderno. Com efeito, a título de elucidação, essa (in)localização do nosso conhecimento é chamada por Franz Fanon (2005) e Gloria Anzaldúa (2007) de corpo-política, aqui apresentada via Walter Mignolo, como opção descolonial dos nossos/deles (indígenas e produtores artísticos-periféricos) discursos.

\begin{abstract}
Assim, o corpo-política e o lado negro e a metade faltante da biopolítica que é apenas a metade da história: o corpo-política descreve as tecnologias descoloniais aplicadas aos corpos que se dão conta que foram considerados menos humanos, no momento em que tomam consciência de que o ato mesmo de ser descritos como menos humanos era uma consideração inumana. Portanto, a falta de humanidade atribuída a todas as populações não europeias é apresentada em atores imperiais, instituições e conhecimentos que tiveram a arrogância de decidir que certas pessoas que não lhes agradavam [ou que não gostavam deles], eram menos humanas. O corpo-política é um componente fundamental do pensamento descolonial, é um fazer descolonial e a opção descolonial para revelar, em primeiro lugar, as táticas da epistemologia imperial para afirmar a si mesma como humanitas do primeiro mundo desenvolvido e, por outro lado, levar o empreender da criação de saberes descoloniais que respondem às necessidades dos anthropos do mundo subdesenvolvido e em vias de desenvolvimento. (MIGNOLO, 2010, p. 33, tradução nossa). ${ }^{9}$
\end{abstract}

O corpo-politica, entre outras coisas, faz resgatar problemas instaurados no Brasil-colônia como, desde os princípios da chegada dos portugueses, a visão que se tem dos índios enxergados como preguiçosos e como mão de obra imprestável pelos povos que aqui ficaram. Nem mesmo os próprios colonizadores tinham essa má impressão dos povos indígenas que por aqui habitavam quando das suas chegadas. Opinião como a certeza que se sustenta até hoje diante do discurso após-colonial interno que menospreza e caracteriza o indígena, por exemplo, mas a todos os sujeitos excluídos pelos sistemas coloniais (históricos e contemporâneos) que também o são, ao classificá-los de inumanos. Segundo Darcy Ribeiro

O índio era tido, ao contrário, como um trabalhador ideal para transportar cargas ou pessoas por terras e por águas, para o cultivo de gênero e o preparo de alimento, para a caça e a pesca. Seu papel foi também preponderante nas guerras aos outros índios e aos negros quilombolas. A documentação colonial destaca, por igual, as aptidões dos índios para ofícios artesanais, como carpinteiros, marceneiros, serralheiros, oleiros. Nas missões jesuíticas tiveram oportunidade de se fazerem tipógrafos, artistas plásticos, músicos e escritores. (RIBEIRO, 1995, p. 99).

Também sinaliza essa discrepância do entendimento da periferia em relação à urbanidade predial das cidades as colocações de Lima (2014, p. 105-106):

\begin{abstract}
Embora historicamente a heterogeneidade de situações periféricas seja imensa, a desvalorização simbólica (BOURDIEU, 1999) da periferia permitiu/permite a consolidação de mecanismos de discriminação e de preconceitos, com apoio de imagens homogêneas e negativas. Evidências aparecem por toda parte de que a representação corrente da periferia como lugar de subserviência está ultrapassada.
\end{abstract}

Nessa direção, cabe dizer que, enquanto as análises sociológicas, geográficas e urbanísticas tomavam como ponto de partida mecanismos estruturais ou de natureza econômica, a antropologia se debruçava sobre o espaço periférico para investigar atores, modos de vida, cotidiano, formas de lazer, identidades culturais, mobilizações coletivas e processos de subjetivação (NASCIMENTO, 2010). Na perspectiva de

\footnotetext{
9 Así, la corpo-política es el lado oscuro y la mitad faltante de la biopolítica que sólo es la mitad de la historia: la corpo-política describe las tecnologías decoloniales aplicadas a cuerpos que se dan cuenta que fueron considerados menos humanos, en el momento en que toman conciencia de que el acto mismo de ser descritos como menos humanos era una consideración inhumana. Por ende, la falta de humanidad atribuida a las poblaciones no Europeas se presenta en actores imperiales, instituciones y conocimientos que tuvieron la arrogancia de decidir que, ciertas personas que no les gustaban, eran menos humanas. La corpopolítica es un componente fundamental del pensamiento decolonial, el hacer decolonial y la opción decolonial al revelar, primero, las tácticas de la epistemología imperial para afirmarse a sí misma en la humanitas del primer mundo desarrollado y, por otro, al emprender la creación de saberes decoloniales que responden a las necesidades de los anthropos del mundo no desarrollado o en vías de desarrollo.
} 
Magnani (2006) estudos antropológicos buscaram ver a cidade "de perto e de dentro", valorizando o ator social, em contraste com as análises orientadas pelas outras disciplinas sociais.

Em contraponto ao potencial do corpo-política, temos o ego-cogito cartesiano (penso, logo existo) que cria um dualismo entre mente e corpo, entre mente e natureza, persistente na cultura moderna como se tivesse sido pensado ontem, que e assim proclama um conhecimento não-situado, universal, chamado "ponto zero". Ambos, conhecimento cartesiano e o chamado "ponto zero", edificamse e mantém-se no lugar enunciativo europeu, graças à sustentação do pensamento moderno que estabelece melhor que ninguém as fronteiras e os limites que dicotomizam as visões dos mundos. Haja vista que são discursos ponderados por esses sujeitos nórdicos como o Centro do Mundo em todos os sentidos que não dá visão a mais ninguém: dicotomias assentadas em maior idade histórica, cultura mais antiga, economia sólida, do social, do conhecimento e da melhor produção artística para centrarmos a discussão em nosso campo do saber (in)disciplinar aqui investigado.

O "ponto zero" é um ponto de vista que se representa como não tendo ponto de vista, que esconde sempre sua perspectiva local e concreta sob um universalismo abstrato. Desse universalismo emerge a possibilidade de subalternização/ subalternizar todo o pensamento que é plural, que tem um lugar enunciativo específico, como é o caso do discurso indígena ou da arte suburbana que não se comunica em essência com o discurso colonial, estatal, disciplinar e capitalista. Tendo, dentre outras razões, pelo fato de que suas consciências coexistem com sua natureza física e com a natureza ambiental (indígena), analogia com a sua natureza imposta de periférico, com as relações sociais particulares (produção artística urbana) e com as quais ambos, de fato, se relacionam. ${ }^{10}$

Este ponto de nossa reflexão faz esboçar o dualismo que se instaura nos fazeres artísticos indígenas e na visão que se tem das práticas artísticas periféricas, por exemplo. Se de um lado temos a boa impressão do índio estar sempre em evidência graças à sua pele que é carregada de marcas ancestrais e que do mesmo jeito as tatuagens dos corpos periféricos tomam a cena da cultura contemporânea estampando corpos elitistas, por outro lado, de modo muito mais macabro, perverso, pesado e excludente, observa-se que a evidência da produção artística indígena ou dos sujeitos excluídos pelos sistemas político-sociais das cidades põe-se mais abrangente de maneira pior que a produção artística branca ou dos artistas dos centros, por exemplo, que não são vistas como arte pelos discursos postos no e pelo atual sistema e política das artes. ${ }^{11}$

Em outras palavras, da ótica branca e elitista o índio toma a cena das práticas artísticas sempre ilustrando a visão estereotipada do homem branco em relação ao mundo indígena e a produção artística periférica é vislumbrada quando a suposta "ação" social contempla em tendas de plástico branco debaixo de sol escaldante as mazelas das periferias que precisam nessas horas de coloridos nas zonas das cidades sempre descriminadas: saúde, educação, segurança e lazer falando apenas das obrigações do poder público.

Do mesmo jeito a produção do indígena, se ressaltada pelo branco, e a produção artísticas dos sujeitos marginalizados, vistas pela sociedade do

10 "O ego-cogito cartesiano ("Penso, logo existo") é o fundamento das ciências modernas ocidentais. Ao criar um dualismo entre mente e corpo e entre mente e natureza, Descartes conseguiu proclamar um conhecimento não-situado, universal, visto pelos olhos de Deus. A isto o filósofo colombiano Santiago Castro-Gomez chamou a perspectiva do "ponto zero" das filosofias eurocêntricas (Castro-Gomez, 2003). O "ponto zero" é o ponto de vista que se esconde e, escondendo-se, se coloca para lá de qualquer ponto de vista, ou seja, é o ponto de vista que se representa como não tendo um ponto de vista." (GROSFOGUEL, 2008, p. 119-120).

${ }^{11}$ Somos levados diuturnamente a pensar que o índio e o sujeito excluído dos sistemas mundo-moderno são bem tratados por esses. O índio como participante do sistema identitário do homem supostamente branco - RG, CPF, Título de Eleitor, CNH etc. Do mesmo jeito o artista grafiteiro ou do picho é levado ao Museu e às galerias institucionais como artistas que nem são ou serão se continuados vistos por esses únicos sistemas. 
consumo que si entende como intelectualizada, no contexto de produção artística feita por índio ou no de arte produzida pelos indivíduos dos submundos citadinos, corroboram a ilustração do discurso artístico posto pelo homem branco como estereótipo da sociedade que se entende como branca e civilizada. É na produção artística indígena que a arte do índio citadino tem "dois pesos, duas medidas" porque é sempre vista pela ótica de uma estética do centro e nunca fora desta, no caso de Mato Grosso do Sul, privilegiada por uma estética produzida por periferia com ares de centros que vê as fronteiras como obstáculos (dis)simulados pelo sistema mundo aqui instaurado.

Os problemas da produção artístico-cultural das margens estão nas dubiedades do olhar estético dos sistemas que (de)limitam às artes a problemática dessa produção não fazer ocupação dos espaços públicos destinados por esses sujeitos e práticas da exclusão. Nesse sentido, temos a certeza de que o índio é "O" sujeito de um discurso enunciado em um lugar ou a partir de um lugar subalterno cavado pelo fosso colonial; a zona suburbana também "É" um lugar do não-ouvido, ainda que fale, pelas ações dos poderes instituídos; portanto, ambos, índios e moradores (ex)ternos aos centros, são os sujeitos que apenas são reconhecidos como tais, por isso grafado "O" e "É", quando convêm aos discursos hegemônicos (dis)postos a fazê-los.

O eurocentrismo torna-se, portanto, uma metáfora para
descrever a colonialidade do poder, na perspectiva
da subalternidade. Da perspectiva epistemológica,
o saber e as histórias locais europeias foram vistos
como projetos globais, desde o sonho de um Orbis
universalis christianus até a crença de Hegel em
uma história universal, narrada de uma perspectiva
que situa a Europa como ponto de referência e de
chegada. A história universal contada por Hegel é
uma história universal na qual a maioria dos atores
não teve a oportunidade de ser também narradores.
(MIGNOLO, 2003, p. 41).

As histórias locais de índios e mesmo de brancos que estão situados às margens da sociedade branca dominante (os moradores das regiões periféricas das cidades) têm suas narrativas sistematizadas pelas ideologias mercantilistas em virtude da atenção que se quer dar ao mercado consumidor interno e externo ou a uma ideia de identidade cultural forjada na ilusória noção de união e atenção a todos. O Estado-nação, nesse sentido, coopta as narrativas indígenas e marginais a contento às suas necessidades e oferece em troca, a preço nada irrisório, um assistencialismo de má qualidade e um reconhecimento que está situado entre as fronteiras do ser no/do mundo excluído, mas poder transitar/conviver "livremente" entre os limites do mundo civilizado. Esse trânsito "livre" dá-se exatamente na constituição ou na relação das histórias locais desses sujeitos contarem o que os projetos globais querem ouvir.

Neste sentido, o índio não anda mais pelado pela cidade para se fazer ser reconhecido como branco e para passar pelos limites das cidades, vistos da ótica do branco, e para se fazer passar desapercebido como índio veste-se de branco ao transitar no seu próprio limite territorial como pode, quando visto do olhar de um igual seu. Do mesmo jeito o sujeito que produz arte periférica é delimitado a trabalhar em espaços específicos para que seja reconhecido como "produtor" de arte para ter trânsito nas cidades constituídas de poderes; enquanto que suas obras verdadeiramente artísticas limitam-se aos espaços inapropriados dos guetos das cidades - na zona suburbana dos centros dessas cidades - que os poderes insistem em não reconhecer e não os querem reconhecidos pela sociedade do sistema.

O projeto global europeu homogeneizou todo um sistema cultural latino-americano implantado graças ao processo colonial de invasão, cristianização e mortandade em massa em toda esta região. Da mesma forma os projetos homogeneizadores contemporâneos - discursivos, políticos, econômicos, estabelecidos por e em questões de gênero e línguas e por relações de diferenças sociais - continuam implementando a exclusão de culturas e práticas artístico-culturais 
e produções de conhecimentos que não estejam vinculadas à irrealidade histórico-cultural europeia (estética moderna) explanada aos lugares excluídos como nossas.

Portanto, a produção artística periférica ou as práticas culturais indígenas, ainda que tomadas pela ótica teórico-discursiva que privilegiem uma leitura coerente de seus resultados produzidos em relação às suas questões sociais, estarão sempre balizadas para os discursos que homogeneízam as práticas e as culturas em fazeres puramente simbólicos como NÃO-qualificados para fazerem inscrições diferentes às quais essas práticas e sujeitos ocupam. Por conseguinte, toda a reflexão que produz conhecimento que também emerge desses lugares excluídos tem rebaixado pelos discursos hegemônicos - sejam os instalados via colonização europeia, sejam dos discursos que se estabeleceram nas regiões ainda que vistas como periféricas da ótica de centros aos quais estão circunscritos - o seu grau de importância/ relevância/produtores de conhecimentos e são tornados populares ou estigmatizados em como simples saberes populares com reconhecimentos apenas locais.

Creio que se deveria compreender saberes subjulgados como outra coisa, algo que de certa forma é totalmente diferente, isto é, todo um sistema de conhecimento que foi desqualificado como inadequado para suas tarefas ou insuficientemente elaborado: saberes nativos, situados bem abaixo na hierarquia, abaixo do nível exigido de cognição de cientificidade. Também creio que é através da reemergência desses valores rebaixados (tais como os saberes desqualificados do paciente psiquiátrico, do doente, do feiticeiro - embora paralelos e marginais em relação à medicina - ou do delinquente etc.) que envolvem o que eu agora chamaria de saber popular [le savoir des gens] embora estejam longe de ser o conhecimento geral do bom senso, mas, pelo contrário, um saber particular, local, regional, saber diferencial incapaz de unanimidade e que deve suas forças apenas à aspereza com a qual é combatido por tudo à sua volta — que é através do reaparecimento desse saber, ou desses saberes locais populares, esses saberes desqualificados, que a crítica realiza a sua função. (FOUCAULT apud MIGNOLO, 2003, p. 44).
O que "salva" os discurso subordinados artísticos ou teóricos - dos sistemas patriarcais coloniais (modernos e/ contemporâneos) ou políticos é que os princípios hegemônicos vêm sendo "desmontados" pelas próprias forças que esses insistem em desqualificar. O poder universal do pensamento colonial acaba por estar ruindo, ainda que aos poucos, sobre a pluralidade dos saberes subalternizados, exatamente porquemuitos outros discursos e práticas artístico-culturais silenciados acabam balbuciando (ACHUGAR, 2006) narrativas contra-hegemônicas dentro do próprio contexto hegemônico. Portanto, a ideia de que o pensamento colonial é um projeto universal que absorve os discursos plurais subalternos vem ruindo dia a dia, ainda que com dificuldades e com o constante encontro de fronteiras disciplinares, porque "hoje, esta ideia está em processo de 'desmontagem' precisamente porque aqueles que foram negados - e àqueles que, no melhor dos casos, foi dada a opção de se integrar à colonialidade - hoje dizem: 'Não, obrigado, mas não; minha opção é descolonial"” (MIGNOLO, 2005, p. 217).

Esse processo de desmontagem é a melhor resposta dada à recolonização das populações indígenas, diante da exposição e imposição que são feitas em relação a essas populações, e à macaqueação institucionalizada da cultura que fazem também com a arte urbana, ao licitá-los índios e artistas urbanos - aos locais predeterminados pelos sistemas que insistem em reafirmar que todos nós somos iguais. Do mesmo jeito a história indígena, a arte da rua ou as produções artísticoculturais indígenas, seus conhecimentos, suas espiritualidades e crenças, suas formas de expressão, mantidas pelo sistema epistemológico descolonial, também são significações de desmontagem contra a ideia de recolonização dos mundos paralelos ao suposto mundo-centro. Igualmente a produção de conhecimento que toma deste discurso aqui posto é uma desmontagem da ideia tradicional de História, Teoria, Filosofia, Sociologia postas. Pois, como 
João Cabral de Melo Neto bem constrói para o desfecho de sua ode à subalternidade do migrante nordestino, a vida é Ribeirinha também em Mato Grosso do Sul:

\author{
[...] E não há melhor resposta \\ que o espetáculo da vida: \\ vê-la desfiar seu fio, \\ que também se chama vida, \\ ver a fábrica que ela mesma, \\ teimosamente, se fabrica, \\ vê-la brotar como há pouco \\ em nova vida explodida; \\ mesmo quando é assim pequena \\ a explosão, como a ocorrida; \\ como a de há pouco, franzina; \\ mesmo quando é a explosão \\ de uma vida Severina. (MELO NETO, 2016, p. 28).
}

É um espetáculo da vida marginal, ou seria melhor dizer que é o espetáculo das vidas marginalizadas pelos sistemas-mundos, histórico e contemporâneo, que podem ser, portanto, interpretados como o lugar da heterotopia de Foucault onde a nãohomogeneidade não condena à uma "morte em vida" os sujeitos que representam a diferença frente ao que representa a força do que domina. "Dois pesos, duas medidas", desta perspectiva foucaultiana da heterotopia, constitui-se agora na vida $=$ a não-morte da arte urbana e do índio citadino (ambos circundados pelas suas práticas e conhecimentos culturais), ainda que dentro, entre, cercado, envoltos às fronteiras (di)simuladas pelo "cogito" sociocultural contemporâneo (pobres e índios não são gente), se vislumbrados por estéticas outras, estéticas periféricas como epistemologias para as suas práticas artísticas ou não, mas culturais.

A paráfrase nominal que propomos ao pensamento cartesiano está assentada na ideia de que ainda que não pense, o sujeito sempre existe, produz arte e conhecimento indiferentemente do reconhecimento de algum discurso que é visto como validador de alguma coisa. De modo bastante contundente, o reconhecimento pelas esferas pública ou privada das práticas do índio ou dos sujeitos que vivem às margens das cidades, como reprodução de artefatos artísticos assentados em discursos históricos e hegemônicos, deve estar sendo pensado exclusivamente da ótica do homem branco, cara pálida e elitista. Não da ótica de quem (re)produz esses "objetos" que estão atravessados de significação simbólico-cultural suas e dos sistemas sociais aos quais pertencem. Olhar essas produções está para muitos, mas visualizá-las na maior abrangência das suas representações, com toda certeza, está para bem poucos dos sujeitos que estabelecem limites entre si e os Outros que, erroneamente, julgam as diferenças desses Outros como anomalias para um projeto egocêntrico e excêntrico de mundo branco.

Por último, a imparcialidade com que são tratados os discursos dos índios e os discursos artísticos produzidos aquém dos centros urbanos, em relação ao que é produzido pelo homem branco e entre os limites citadinos, está na implantação de limites reais e imaginários nos espaços que se tornam (dis)simulação por essas fronteiras da e na contemporaneidade. A arte urbana ou o índio, urbanizados pelos poderes políticos, culturais e sociais, que os encarceram, de um modo bastante preciso, apresentam visualidades contraditórias em relação a esses sujeitos marginalizados.

Apesar de a injustiça estabelecer-se na arte urbana ou para o índio de toda a América Latina ou para qualquer outra cultura e produção inscritas na insígnia de periférica, situadas em diferentes lugares espalhados pelo mundo, optamos por tomar como escopo de discussão neste trabalho o problema da arte e o caso de aldeias urbanas "civilizados" em Campo Grande, Mato Grosso do Sul - Brasil — pelos discursos que tomam sempre da perspectiva Moderna para ressaltar essas fronteiras que imprimem limites (dis)simulados que tomam a produção da arte urbana e a cultura do índio citadino locais com tratamentos e formas completamente diferentes das que são estabelecidas 
para a produção artística do homem branco e morador dos centros; que sempre ditou as regras do jogo que consecutivamente tem um perdedor comum que ocupa um lado onde estão os sujeitos mais fracos pela possibilidade de melhor explicação das questões apresentadas nessa cultura e práticas.

Partindo do princípio de aproximação, a discussão centrou-se na proposição de que uma formulação epistemológica periférica pode tornar a prática artística indígena ou as culturas excluídas pelos discursos hegemônicos de qualquer "centro" do poder, pensadas de dentro para fora, não o inverso, como produção de arte, como cultura e como produtores de conhecimentos graças as suas diversalidades biogeográficas (BESSAOLIVEIRA, 2016) e sem o estabelecimento de fronteiras como algo binário. Como algo que separa apenas, ao invés de somente ajuntar as diferenças, divergências, diversalidades, particularidades, especificidades etc. Ainda tomamos esses sujeitos locais como referência exatamente porque é do "nosso lugar" epistêmico que melhor falamos, pensamos e produzimos arte e conhecimentos.

\section{Referências}

ACHUGAR, H. Planetas sem boca: escritos efêmeros sobre arte, cultura e literatura. Tradução de Lyslei Nascimento. Belo Horizonte: Ed. da UFMG, 2006.

ANZALDÚA, G. Borderlands: la frontera (the new mestiza). São Francisco: Aunt Lute Books, 2007.

BESSA-OLIVEIRA, M.A. Biogeografias ocidentais/ orientais: (i)migrações do bios e das epistemologias artísticas no front. Cadernos de Estudos Culturais: Ocidente/Oriente: Migrações, Campo Grande, v. 8, n. 15, jan./jun.. p. 97-144, 2016.

BLUMENBERG, H. Teoria da não conceitualidade. Tradução de Luiz Costa Lima. Belo Horizonte: Ed. da UFMG, 2013.

FANON, F. Os condenados da terra. Tradução de Enilce Alberfaria Rocha e Lucy Magalhães. Juiz de Fora: Ed. da UFJF, 2005.
GROSFOGUEL, R. "Para descolonizar os estudos de economia política e os estudos pós-coloniais: transmodernidade, pensamento de fronteira $\mathrm{e}$ colonialidade global." Revista Crítica de Ciências Sociais, Coimbra, n. 80, p. 115-147, 2008. Disponível em: <https://ialnet.unirioja.es/servlet/ articulo?codigo $=2763903>$. Acesso em: 15 jul. 2016 .

HALL, S. "A centralidade da cultura: notas sobre as revoluções culturais do nosso tempo." Educação \& Realidade, Porto Alegre, v. 22, n. 2, p. 15-46, jul./dez. 1997.

HISSA, C. E. V. A mobilidade das fronteiras: inserções da geografia na crise da modernidade. Belo Horizonte: Ed. da UFMG, 2002.

LIMA, V. C. "Juventude e política cultura na periferia brasileira: nova dominação ou cena potente?." In: ALMEIDA, M. I. M.; LIMA, F. D. B. (Org.). Arte jovem: redesenhando fronteiras da produção artística e cultural. Rio de Janeiro: Gramma, 2014. p. 101-123. (Subjetividades Juvenis na Contemporaneidade, v. 2).

MELO NETO, J. C. Morte e vida severina. Belém: Núcleo de Educação à Distância da Universidade da Amazônia. Disponível em: <www.nead.unama.br>. Acesso em: 25 jul. 2016.

MIGNOLO, W. D. "Desobediencia epistémica II. Pensamiento independiente y libertad De-colonial." Otros Logos: Revista de Estudios Críticos, Neuquén, ano 1, n. 1, p. 8-42, 2010.

MIGNOLO, W. D. Histórias locais/ projetos globais: colonialidade, saberes subalternos e pensamento liminar. Tradução de Solange Ribeiro de Oliveira. Belo Horizonte: Ed. da UFMG, 2003.

MIGNOLO, W. D. La idea de América Latina: la herida colonial y opción decolonial. Tradução de Silvia Jawerbaum e Julieta Barba. Barcelona: Gedisal, 2005.

RIBEIRO, D. O povo brasileiro: evolução e sentido do Brasil. São Paulo: Companhia das Letras, 1995.

Recebido em: 21 ago. 2016. Aceito em: 12 jan. 2017 